\title{
Modelagem Matemática na Educação Básica: um olhar para o currículo
}

\author{
Mathematical Modeling in Basic Education: a look at the curriculum
}

\author{
Samuel Francisco Huf \\ Dionísio Burak \\ Nilcéia Aparecida Maciel Pinheiro
} \begin{abstract}
organização curricular respalda as necessidades para a adoção da Modelagem Matemática na Educação Básica? No encalço dessas questões, realiza-se uma pesquisa bibliográfica de natureza qualitativa a partir de artigos disponíveis nas bases Scopus, Scielo, Portal de Periódicos da CAPES, Web of Science e Science Direct. As análises evidenciam inquietações a respeito do currículo por autores que buscam utilizar a Modelagem Matemática no âmbito da Educação Matemática. Os resultados apontam as teorias curriculares crítica e pós-crítica como as que mais se aproximam dos objetivos de formação dos estudantes por meio da Modelagem Matemática.
\end{abstract}

Resumo: Este artigo tem como objetivo explicitar formas de organização curricular que respaldam a implementação da Modelagem Matemática na Educação Básica. Nesse sentido, as questões norteadoras são: $O$ que se mostra sobre a Modelagem Matemática na Educação Básica, em relação à organização curricular, em um conjunto de artigos analisados? Qual forma de

Palavras-chave: Modelagem Matemática. Currículo. Educação Matemática.

Abstract: This article aims to explain the forms of curricular organizations that support the implementation of Mathematical Modeling in Basic Education. In this sense, the guiding questions are: What is shown about Mathematical Modeling in Basic Education, concerning the curricular organization, in the analyzed articles? What form of curricular organization supports the needs for the adoption of Mathematical Modeling in Basic Education? In the pursuit of these questions, qualitative bibliographic research was carried out based on articles available in the Scopus, Scielo, CAPES Journal Portal (Portal de Periódicos da CAPES), Web of Science, and Science Direct data bases. The analyzes show concerns about the curriculum by authors who seek to use Mathematical Modeling within the scope of Mathematical Education. The results point out the critical and post-critical curricular theories as those that come closest to the students' training objectives through Mathematical Modeling.

Keywords: Mathematical Modeling. Curriculum. Mathematics Education.
Samuel Francisco Huf Doutorando em Ensino de Ciência e Tecnologia (UFTPR). Bolsista da Coordenadoria de Aperfeiçoamento de Pessoal de Nivel Superior (CAPES). Paraná, Brasil.

(iD) orcid.org/0000-0002-5917-7746 $\bowtie$ samuelfhuf@gmail.com Dionísio Burak Doutor em Educação. Professor do Programa de Pós-Graduação em Educação da Universidade Estadual de Ponta Grossa (UEPG) e Programa do Programa de PósGraduação em Ciências Naturais e Matemática da Universidade Estadual do Centro-Oeste (Unicentro). Paraná, Brasil. (iD) orcid.org/0000-0002-1345-1113 $\bowtie$ dionisioburak@gmail.com

Nilcéia Aparecida Maciel Pinheiro Doutora em Educação Cientifica e Tecnológica. Professora do Programa de Pós-Graduação em Ensino de Ciência e Tecnologia da Universidade Tecnológica Federal do Paraná (UFTPR), campus Ponta Grossa. Paraná, Brasil.

iD orcid.org/0000-0003-3313-1472 $\triangle$ nilceia@utfpr.edu.br

Recebido em 31/03/2020 Aceito em 28/05/2020 Publicado em 22/06/2020 


\section{Introdução}

A nossa vivência na Educação Básica aponta o desinteresse mostrado pela maioria dos estudantes como um possível problema enfrentado para a atuação docente. Desinteresse este, que pode ser uma decorrência do modo de ensino realizado, que se entende ainda, em maior parte, centrado em repetições e "decorebas"; ou em uma única forma para a abordagem dos conteúdos, visando à avaliação que, muitas vezes, é realizada apenas com o propósito de cumprir um planejamento elaborado no início do período escolar, sem a presença do estudante, e que passada a avaliação os conteúdos são esquecidos. Essa preocupação com a avaliação se constitui em cumprir normas da escola, em se ter uma "nota", muitas vezes, sem levar em conta aquilo que é essencial em uma avaliação, como saber se o estudante aprendeu, quais as dificuldades ainda presentes quanto ao conteúdo e quais os tipos de lacunas que ainda precisam ser retomadas. A avaliação deve ser compreendia, tanto pelos estudantes quanto pelo professor, como "prática reflexiva" (SILVA e FRANCO, 2019, p. 749).

Ainda, a forma de avaliar, quando prioriza apenas o quantitativo em detrimento do qualitativo, pode também se enquadrar nos motivos que causa o desinteresse por parte dos estudantes em aprender Matemática, que juntamente a outras condições - como ausência às aulas, a falta de atenção da família e pouco estímulo para o estudo - se constituem fortes empecilhos para o ensino com vistas à aprendizagem da Matemática na Educação Básica.

Para reverter essa situação da atuação docente, o professor pode assumir um papel mais expressivo na formação dos estudantes, procurando não oferecer teoremas, definições e regras prontas e acabadas a serem memorizadas, mas contribuir para que os estudantes formem conceitos e construam seus conhecimentos matemáticos, tendo como ponto de partida as suas vivências, ainda que num primeiro momento. Assim, posteriormente, podem atuar como integrantes da sociedade e participar ativamente das tomadas de decisões da comunidade, com consciência política, social e ambiental. Isso vem ao encontro do que ponderou Burak (1992) ao se referir que a preocupação da escola deve ser em preparar as novas gerações para que consigam trilhar seus próprios caminhos, "onde a capacidade de reflexão e decisão possa ser exercitada através de ações concretas e não se constituam apenas em discurso" (p. 322). No entanto, percebemos que ainda pouco se avançou quanto à essa questão.

Diante disso, o professor deve buscar por novas metodologias para o ensino e aprendizagem de Matemática tornando o processo mais significativo. Como destaca Moran (2015, 
p. 19), "a educação precisa incorporar mais as dinâmicas participativas, como as de autoconhecimento (trazer assuntos próximos à vida dos alunos), as de colaboração (trabalhos de grupos, de criação grupal) e as de comunicação (como o teatro ou a produção de vídeo)". Entendemos que isso é potencializado pela Modelagem Matemática1 em uma perspectiva de Educação Matemática, conforme os indicam os estudos de Huf (2016), Komar (2017), Castro (2017), Leite (2018) e Silva (2018).

Ao refletir sobre as práticas de sala de aula com vistas ao ensino de Matemática, retratadas nas pesquisas citadas, entendemos que o quadro atual de desinteresse dos estudantes pode ser modificado a partir da adoção de abordagens que privilegiam, inicialmente, o trabalho a partir de suas cotidianidades. Dentre as abordagens que vêm ao encontro dessas possibilidades para os processos de ensino e de aprendizagem de Matemática, escolhemos a concepção de Modelagem que é fundamentada na Educação Matemática, a qual segundo Burak (2019) possui um constructo científico interdisciplinar na perspectiva de Higginson (1980). Essa abordagem abrange, além da Matemática, as áreas da Educação que dão sustentação para um ensino com vistas à aprendizagem. Além do método qualitativo - que permite pontuar as dificuldades dos estudantes que envolvem a compreensão dos conceitos, a significação dos conteúdos e a falta de contextualização -, ampara-se no objeto da Educação Matemática cuja prioridade são os processos de ensino e de aprendizagem. Também nos identificarmos com os encaminhamentos para a realização de atividades nessa concepção.

Assim, na concepção escolhida, a Modelagem Matemática "constitui-se em um conjunto de procedimentos cujo objetivo é construir um paralelo para tentar explicar, matematicamente, os fenômenos presentes no cotidiano do ser humano, ajudando-o a fazer predições e tomar decisões" (BURAK, 1992, p. 62).

No entanto, os professores, ainda atualmente, encontram dificuldades para adotar a Modelagem Matemática, em sala de aula. Dentre as várias dificuldades, uma delas consideramos que reside na formação imprópria do professor, no âmbito da licenciatura, para o trabalho com a modelagem na Educação Básica; outra delas situa-se no recinto da própria escola em relação ao currículo, quando este é compreendido apenas como um rol de conteúdos que devem ser cumpridos de forma linear, o que pode frustrar qualquer iniciativa de utilização seja da Modelagem

\footnotetext{
1 Adotamos a grafia de "Modelagem Matemática" em maiúscula quando nos referimos à uma concepção; e "modelagem matemática" em minúscula quando estamos tratando de uma atividade realizada em sala de aula.
} 
ou de quaisquer outras tendências da Educação Matemática que postulam a possibilidade de ruptura com o currículo linear.

O currículo, na forma que se apresenta na maior parte das escolas brasileiras e no entender do corpo docentes dessas instituições, ainda se mostra comprometido com uma concepção tradicional e cartesiana. A maioria dos planejamentos segue os conteúdos, muitas vezes, com base nos livros didáticos, que, em sua maioria, seguem uma visão linear dos conteúdos, conforme Silva (2010), uma lista a ser transmitida pelos professores e memorizada pelos estudantes por meio de repetições. O currículo na perspectiva tradicional e cartesiana segue a racionalidade técnica e baseia-se "nos componentes objetivos, conteúdos e métodos, obedece a definições obsoletas de objetivos de uma sociedade conservadora" (D'AMBROSIO, 2009, p. 88). As ações a serem desenvolvidas, em âmbito escolar, são pré-determinadas e estabelecidas pelos professores que, em muitas vezes, não despertam nos estudantes a capacidade da argumentação e da análise crítica de situações a enfrentarem no meio onde estão inseridos.

Diante disso, adotamos a Educação Básica como ambiente de pesquisa e estabelecemos como objetivo para essa investigação identificar, após analisar trabalhos que abordam a Modelagem Matemática no viés da Educação Matemática, a forma de organização curricular que pode respaldar a implementação da Modelagem Matemática nesse nível de ensino.

As questões que direcionam a pesquisa são: 0 que se mostra sobre a Modelagem Matemática na Educação Básica, em relação à organização curricular, em um conjunto de artigos analisados? Qual forma de organização curricular acomoda as necessidades para a adoção da Modelagem Matemática na Educação Básica?

Para alcançar o objetivo e responder as questões, adotamos uma pesquisa bibliográfica de abordagem qualitativa na perspectiva de Gil (2008). A seguir, após as descrições dos procedimentos metodológicos que permitiram a reunião de algumas referências, tecemos articulações entre os referenciais. Essas articulações estão explicitadas em uma seção principal e em três seções secundárias, respectivamente denominadas: Uma idealização de currículo para a Educação Básica com vistas aos objetivos da Modelagem Matemática na Educação Matemática; Evidências de preocupação de pesquisadores em Modelagem Matemática com o Currículo; A concepção de Modelagem Matemática assumida; e Teorias curriculares que mais respaldam a implementação da Modelagem Matemática em sala de aula. Por fim, as conclusões. 


\section{Métodos e procedimentos}

Na busca de respostas às questões pré-estabelecidas, a pesquisa se constituiu como bibliográfica de natureza qualitativa. Para isso, buscamos trabalhos desenvolvidos com Modelagem Matemática e que tratassem de currículo. As buscas foram realizadas em fevereiro de 2020 e se deram nas bases de dados Scopus, Scielo, Portal de Periódicos da CAPES, Web of Science, Science Direct. As combinações utilizadas para as buscas com operadores booleanos foram: ("Mathematics Modeling" AND "Basic education" AND "curriculum") e ("Elementary schools" AND "mathematics curriculum" AND "Mathematics Modeling").

A partir da busca, foram obtidos 96 artigos. Após eliminarmos resultados repetidos, a filtragem se deu por meio da leitura dos títulos, palavras-chaves e resumos. Essa filtragem foi necessária em vistas de obtermos resultados que não condizem com o foco da pesquisa, sendo artigos que não abordavam a Educação Básica e outros por não tratar da Modelagem Matemática na perspectiva da Educação Matemática. Assim, as referências consideradas são: Arroyo (2007); Burak (2010); Burak e Martins (2015); Caldeira (2004, 2005, 2015); Caldatto, Pavanello e Fiorentini (2016); Cuoco, Goldenberg e Mark (1996); Forner (2015); Hornburg e Silva (2007); Klüber e Burak (2008); Oliveira (2017); Pinheiro (2009); e Silva (2010).

Elencadas essas referências, realizamos a leitura destacando pontos relevantes sobre a Modelagem Matemática e sobre o Currículo em termos de concepções e de posicionamento teórico dos autores no contexto da Educação Matemática com vistas em responder às questões estabelecidas e enunciadas anteriormente.

A seguir apresentamos a perspectiva dos autores supracitados e tecemos considerações adotando como elemento norteador a busca por respostas às questões da pesquisa.

\section{Uma idealização de currículo para a Educação Básica com vistas aos objetivos da Modelagem Matemática na Educação Matemática}

A preocupação de o que ensinar para as futuras gerações e como ensinar é uma constatação desde o surgimento das primeiras escolas, o que resulta diferentes propostas curriculares para cada época. Cuoco, Goldenberg e Mark (1996), no artigo titulado Habits of Mind: an organizing principle for Mathematics curricula, tecem discussões em torno das questões: Que matemática deve ser ensinada às futuras gerações? "Teoria dos grafos ou geometria sólida? 
Geometria analítica ou geometria fractal? Modelagem com álgebra ou modelagem com planilhas?" (p. 375). Conforme os autores, essas são questões erradas que levam os cursos de Matemática ser vistos como mecanicistas desde os níveis elementares até a formação superior. Ainda para os autores, se uma nova proposta curricular for idealizada a partir dessas questões para um curso, desde o elementar até o superior, esse tende a seguir um caminho que leva estudantes por gerações a aprender na escola algo que chama de Matemática, mas que não tem nada a ver com a Matemática aplicada fora da sala de aula e muito menos com a forma com que a Matemática é construída.

Quando se trata de Ensino e/ou Educação Matemática é encontrado na literatura da área críticas, até mesmo a programas de Pós-Graduação que se rotulam de formação de professores para atuação na Educação Básica, mas que prezam a Matemática pela Matemática. Isso se constitui como fruto do sistema de formação que preza a formação matemática em detrimento da pedagógica. Uma análise é apresentada por Caldatto, Pavanello e Fiorentini (2016), no artigo titulado PROFMAT e a formação do professor de Matemática: uma análise curricular a partir de uma perspectiva processual e descentralizadora. Neste artigo, os autores argumentam que a Matemática em um viés de Matemática pura, da Matemática pela Matemática, pouco contribui para a formação do professor da Educação Básica. Após uma intensa discussão, os autores concluem que

\begin{abstract}
o processo formativo privilegiado pelo PROFMAT é, na verdade, um processo descontínuo de formação do professor de Matemática, pois pressupõe, de um lado, que ele é capaz de garantir a qualificação do professor de Matemática, promovendo apenas uma formação matemática técnica e formal desconectada da formação didático-pedagógica e da atividade complexa de ensinar e aprender Matemática com alunos com diferentes níveis cognitivos e culturais. Essa formação é também descontínua e inócua no alcance de seus objetivos, porque ignora que a Matemática escolar é de outra natureza e apresenta outros desafios e demandas que caberia ao mestrado profissional tomá-los como objeto de estudo e ponto de partida e de chegada do processo formativo. (CALDATTO, PAVANELLO e FIORENTINI, 2016, p. 924).
\end{abstract}

Retomando a perspectiva de Cuoco, Goldenberg e Mark (1996), compreendemos que, tanto em nível da Educação Básica quanto em nível de Ensino Superior e de Pós-Graduação, cujo foco são o ensino e a aprendizagem para a Educação Básica, uma organização curricular deveria ser proposta a partir de "hábitos da mente", para que os estudantes participem do processo, que desenvolvam habilidades de criar, inventar, conjecturar e a partir de experiências possam testar seus resultados aceitando-os ou refutando-os. 
Nesse âmbito, um currículo deveria ser pensado a partir dos estudantes para que eles possam desenvolver novas experiências. Um currículo que propicie a eles desenvolver seus próprios hábitos e que saibam que conteúdo e/ou conceito matemático usar em cada situação do dia a dia. Um currículo que prepare os estudantes para que saibam descrever com detalhes os encaminhamentos utilizados na resolução de um problema inerente de sua vivência. Um currículo que oportunize aos estudantes criar suas próprias notações. Um currículo que propicie formar estudantes escritores que descrevem suas opiniões, pensamentos, conjecturas e que saibam defender suas opiniões; que se sintam livres para questionar um o trabalho do outro. Um currículo que contribua para os estudantes que pretendem seguir para estudos mais avançados, mas que também sirva para aqueles que não continuarão seus estudos (CUOCO, GOLDENBERG e MARK, 1996).

Arroyo (2007, p. 28) destaca que os conteúdos da forma que são propostos aos estudantes não consideram "a vivências e apenas se preocupam com que aprendam competências e habilidades para um mercado futuro de trabalho idealizado para poucos." 0 autor aponta a necessidade de não esquecer

\begin{abstract}
as formas de trabalho na produção camponesa, na agricultura familiar; a resistência dos povos do campo à destruição dessas formas de produção e trabalho; a resistência a perder seus saberes sobre essas formas de trabalho. Esses saberes sobre essa pluralidade de formas de trabalho não deveriam entrar nos currículos? Os alunos não têm direito a esses conhecimentos vivos? Por que não os incluir com destaque nos currículos? 0 acesso a esses conhecimentos acumulados não Ihes seria de extrema necessidade para conhecer-se nessa perversa realidade social e economia dos mundos do trabalho? (ARROYO, 2007, p. 28-29).
\end{abstract}

Ao encontro do que abordou Arroyo (2007), a Modelagem Matemática quando trabalhada na perspectiva da Educação Matemática busca uma formação completa para os estudantes envolvidos; mas em nome de uma visão de currículo tradicional, predominante em grande parte das escolas brasileiras, a Modelagem Matemática ainda encontra empecilhos para ser adotada em sala de aula. Isso é explicitado por pesquisadores em Modelagem Matemática que em seus estudos fazem menção ao currículo, tais estudos são discutidos a seguir.

\title{
3.1 Evidências de preocupação de pesquisadores em Modelagem Matemática com o Currículo
}

Levantar as dificuldades dos professores em implementar a Modelagem Matemática na 
Educação Básica, para Caldeira (2015), tem se mostrado como uma vertente de pesquisas no Brasil e no exterior. $O$ autor afirma que uma das dificuldades da adoção e da implementação da Modelagem Matemática no Ensino Básico é em relação a cumprir o currículo se este for compreendido de forma cartesiana, ou seja, uma forma reduzida do currículo em uma "lista de conteúdos que os professores precisam cumprir nas suas instituições, dentro de cada etapa de escolaridade" (CALDEIRA, 2015, p. 54).

Conforme o autor, a forma estrutural dos currículos escolares é constituída por um modo padronizado de pensar e de aprender, e é a visão da classe dominante que estipula o que deve ser ensinado e aprendido no contexto da escola. Com relação à organização curricular vigente, Caldeira (2015, p. 57) cita Foucault (2012), para quem "a escola formata, padroniza, controla e dociliza os corpos daqueles que passam por ela". Para corroborar, ainda, Caldeira (2015, p. 57), apresenta Clareto (2002), que considera que "esses corpos são contingenciados a se comportar, sob o ponto de vista do conhecimento, de uma maneira mais ou menos homogênea", que perpetua a desigualdade, fortalece uma ideologia com características eurocêntricas direcionando ao trabalho e ao consumismo.

Para Caldeira (2005, p. 8) "o currículo deve ser adaptado à realidade do aluno"; isso não significa o estudante só saber o que é de sua realidade, mas que o currículo deve ser repensado.

\begin{abstract}
Assim, é preciso romper a estrutura arbórea com a qual temos representado uma concepção mecânica do conhecimento e da realidade, reproduzindo a fragmentação cartesiana do saber e, ao invés disso, investir numa concepção que subverta essa imagem arbórea pela imagem de rizoma (DELEUZE; GUATTARI, 1980). Numa visão sistêmica, cumprir o programa não é ter que seguir rigorosamente os conteúdos listados nele, mas fazer 0 aluno perceber que determinados conteúdos existem e podem ser aprendidos quando tivermos a oportunidade de percebê-los como instrumentos de compreensão de uma dada realidade, que esteja em interdependência com outros conteúdos que não somente os da matemática por ela mesma. (CALDEIRA, 2015, p. 59-60).
\end{abstract}

Caldeira $(2004)$ e Burak $(1998,2004,2010)$ argumentam que com a Modelagem, os conteúdos deixam de ser totalmente previsíveis, a abordagem desses conteúdos depende da direção tomada pelos estudantes durante o levantamento e a resolução dos problemas e, também, dos encaminhamentos adotados pelo professor. Assim, são os problemas que determinam o conteúdo a ser estudado. Nesse contexto, o currículo torna-se flexível e não segue a ordem apresentada pelos livros didáticos e, muitas vezes, aparecem conteúdos que não estão programados para determinado ano escolar. Assim, a implementação de atividades de modelagem 
matemática com estudantes da Educação Básica "pode conferir um outro significado e ordem aos conteúdos programáticos do currículo" (KLÜBER e BURAK, 2008, p. 25). Klüber (2012, p. 149) ainda destaca que ao "assumir a Modelagem Matemática na Educação Matemática, mudanças curriculares se impõem".

Oliveira (2017), ao fazer análise de atividades de modelagem por ele realizada, quando se refere à organização dos conteúdos matemáticos enfatiza que com modelagem a organização curricular assume outra hierarquia e não pode ser mais compreendida de forma linear. Como destaca, "é possível afirmar que o currículo linear foi rompido, pois cada um dos grupos mobilizou e adotou conceitos e estratégias diferentes para investigação e busca de uma solução para as situações escolhidas por eles próprios" (OLIVEIRA, 2017, p. 514).

Nesse sentido, Forner (2015) destaca que a prática da Modelagem Matemática na Educação Básica poderia oportunizar pensar um currículo a partir do interesse dos estudantes. 0 autor embasa seus trabalhos na compreensão de Modelagem segundo Malheiros (2012), na qual o objetivo da Modelagem "não é apenas que o indivíduo aprenda Matemática e, sim, que ele a utilize para compreender seu entorno, sua realidade e que possa, a partir dela, exercer sua cidadania" (p. 8). Forner (2015) pondera que a Modelagem ainda não está, de fato, na sala de aula pela cobrança de se cumprir na integra o currículo de forma linear, tal cobrança é advinda da comunidade escolar e até mesmo dos pais. A autora acredita "que o caminho seja pensar em uma Modelagem Matemática e o processo de ensino e aprendizagem numa perspectiva de educação libertadora baseada na teoria de Paulo Freire" (FORNER, 2015, p. 6), considerando peças fundamentais a criticidade, a problematização e a autonomia em uma perspectiva de educação libertadora e emancipadora.

Ao analisarmos quais profissionais atuarão na Educação Básica, entendemos que ela não é desvinculada do Ensino Superior, mas a Educação Básica é um reflexo da formação conferida no Ensino Superior. Isso dá respaldo ao que Arroyo (2007) defende com vistas à formação profissional para o corpo docente não mais centrada apenas no "que" e no "como" ensinar a matéria específica, mas que venha atender "múltiplas dimensões da formação e dos processos complexos de formação de um ser humano. Que entenda do papel do conhecimento e da cultura nesses processos de formação" (p. 42).

Desse contexto, podem partir fundamentações as análises para um entendimento de currículo de matemática para a Educação Básica, com as características da Modelagem na 
Educação Matemática na concepção de Burak².

\subsection{A concepção de Modelagem Matemática assumida}

No Brasil, vários pesquisadores desenvolveram e desenvolvem concepções de Modelagem Matemática, dentre eles destacamos: Ademir Donizeti Caldeira, Ana Paula Malheiros, Dionísio Burak, Jonei Cerqueira Barbosa, Lourdes Maria Werle de Almeida, Maria Salett Biembengut e Rodney Carlos Bassanezi. Assumimos àquela concepção que tem explicitamente preocupações com o ensino e a aprendizagem no âmbito da Educação Básica; a partir do seu constructo científico uma concepção de Modelagem Matemática que se embasa e se alinha, além da Matemática nas Ciências Sociais e Humanas, na epistemologia do conhecimento complexo. Nesse entendimento, confere maiores possibilidades, pois articula a Matemática e as áreas da Educação que podem proporcionar um ensino com vistas à aprendizagem. É com esse entendimento que para a realização das práticas com a Modelagem Matemática, segundo Burak (1992, p. 51), têm como princípios: 1) "partir do interesse do grupo de pessoas envolvidas", que segundo Dewey (1978, p. 71) "em interesse, não há simplesmente um sentimento inerte ou passivo, mas alguma coisa de motriz, de dinâmico"; 2) outro ponto nessa metodologia é a coleta dos dados, sempre que possível, realizada no ambiente em que reside o interesse. Para Burak (2010), ao defender o primeiro princípio sustenta-o no campo da Psicologia, pois, nossas ações são movidas por interesse; o segundo princípio está no campo do método, onde "fazem uso do enfoque de corte antropológico, fenomenológico, etnográfico e, todos aqueles que se caracterizam por ser uma variedade da 'observação participante'” (p. 19).

Com a perspectiva de tornar o estudante mais curioso e investigativo, um buscador que desenvolve seu senso crítico, Burak $(1998,2004,2017,2019)$ sugere para a realização de uma prática com modelagem em cinco etapas, sendo: 1) escolha do tema; 2) pesquisa exploratória; 3 ) levantamento do(s) problema(s); 4) resolução dos problemas e o desenvolvimento de conteúdos no contexto do tema; e 5) análise crítica da(s) solução(ões).

A escolha do tema constitui-se do momento inicial do desenvolvimento de uma prática com modelagem matemática, na qual os estudantes e até mesmo o professor opinam sobre temas variados e de interesse comum. Esse momento se constitui propício para se conhecer as ideias,

\footnotetext{
2 Quando referimo-nos à concepção de Modelagem de Burak embasamo-nos em Burak (1992, 1998, 2004, 2010 ,
} 2017, 2019). 
os gostos, os diálogos, e as contribuições dos estudantes. Nesse momento, o professor assume o papel de mediador, possibilitando com que a escolha final do tema seja dos estudantes (KLÜBER e BURAK, 2008).

Definido o tema, prossegue-se em sequência para a segunda etapa, a pesquisa exploratória. Nessa etapa, os estudantes buscam conhecer sobre o assunto relacionado ao tema, a pesquisa pode ser sobre curiosidades, aspectos técnicos, ou ainda outros aspectos sociais, econômicos que podem estar afetos ao tema. Para isso, os estudantes podem utilizar os espaços, além da sala de aula, como a biblioteca da escola, o laboratório de informática, pesquisa in loco, e até mesmo conversas ou entrevistas com técnicos, familiares, amigos e/ou pessoas mais experientes. Aprofundar e desvendar conhecimentos a respeito do tema, "buscar informações no local onde se localiza o interesse do grupo de pessoas envolvidas, além de se constituir em uma das premissas para o trabalho nessa visão de Modelagem é uma etapa importante na formação de um estudante mais crítico." (BURAK, 2010, p. 21). Com essa etapa, os estudantes passam a perceber que o professor não é o detentor de todo o conhecimento a ser adquirido, mas assumese de um mediador entre o conhecimento científico e o conhecimento dos estudantes.

Em posse dos dados da pesquisa realizada, os estudantes são incentivados e orientados a formular problemas, o que se constitui na terceira etapa do processo. Os problemas podem ser desde uma situação mais simples, em forma de questões, como podem ser em forma de situações em que o conteúdo para resolução ainda não esteja presente nos conhecimentos dos estudantes. A formulação ou elaboração de problemas é uma etapa importante do processo, pois o estudante aprende a traduzir dados e informações em situações-problema.

Nessa etapa, os estudantes ainda não precisam se preocupar com os conteúdos matemáticos, esses conteúdos aparecerão e serão pesquisados na etapa da resolução dos problemas. Opondo-se à forma tradicional de tratar os conteúdos matemáticos, na concepção de Modelagem Matemática assumida, são os problemas que irão nortear os conteúdos matemáticos a serem estudados. É a partir dessa perspectiva que a organização curricular poderia ser implementada, um currículo vivo, constituído por todas as relações que se estabelecem no contexto escolar, entre estudante e estudante, e estudante e professor, ultrapassando a visão de currículo restrita ao conteúdo.

Elaborados os problemas, segue-se à quarta etapa, qual seja, resolução do(s) problema(s). Nessa etapa, os estudantes, sob a mediação do professor, buscam o ferramental 
matemático necessário para a resolução que se constitui na forma, no método ou nos cálculos para achar a solução do problema. É nessa etapa que os conteúdos ganham sentido e significado para o estudante, pois eles partem de um tema, realizam pesquisa no contexto do tema, com base na pesquisa é que elaboram os problemas, e buscam subsídios nos conteúdos matemáticos para a resolução; assim eles passam a perceber o porquê do conteúdo naquele momento. Aqui podemos retomar os objetivos de um currículo, como já apresentado, a partir dos "hábitos da mente" defendido por Cuoco, Goldenberg e Mark (1996) que propicie aos estudantes saber o que usar e quando usar.

Quando o conteúdo necessário para resolver o problema ainda não faz parte do conhecimento do estudante, cabe ao professor, como mediador entre o conhecimento científico estabelecido e o conhecimento do estudante, favorecer a construção desse conhecimento. Para isso, o professor pode valer-se de distintas formas, como por exemplo, das investigações matemáticas com preparação de material de formação de conceitos matemáticos a partir da busca dos conteúdos em livros textos ou até mesmo na internet, ou ainda, partir de situações empíricas para os primeiros resultados, e na sequência desenvolver o conteúdo de forma analítica, com alguma formalização matemática (BURAK, 2010). Outra forma é a utilização de "organizadores prévios" (AUSUBEL, 2003) como pressupostos para aprendizagem significativa; como destaca Aragão (1976), esses organizadores se constituem em uma forma de manipulação deliberada da estrutura cognitiva, que podem ser entendidos como um conjunto de procedimentos, que envolvem vários níveis de ação com vistas a alcançar um objetivo ou resultado, nesse caso a compreensão ou construção de um conteúdo.

O importante nessa etapa é fazer com que o estudante articule, pense, discuta com seus colegas de grupo e de outros grupos e busque alguma forma de apresentar os resultados. Corroborando com o que foi apresentado em Cuoco, Goldenberg e Mark (1996), a organização curricular deveria formar estudantes que saibam defender suas opiniões, que se sintam livres para questionar.

Em continuidade à resolução do(s) problema(s), tem início a quinta etapa da Modelagem, a análise crítica da(s) solução(ões) encontradas. Trata-se de um momento rico em que os estudantes juntamente com o professor analisam e discutem as soluções apresentadas. Nessa etapa, conforme Burak (2010, p. 24), podem ser "analisados os aspectos matemáticos de uma solução", bem como, dentre outros os: sociais, econômicos, culturais e ambientais. Em relação 
aos aspectos matemáticos, "pode-se analisar a coerência e a consistência lógica da solução ou das soluções encontradas. Etapa em que se discute com o grupo ou grupos os cuidados com a linguagem, com as restrições que se fazem necessárias em muitas ocasiões" (BURAK, 2010, p. 24). É a etapa propícia para comentar as diferenças e aproximações das soluções empíricas e das mais formais, pois na Educação Básica geralmente "se parte do empírico para ao formal" (BURAK, 2010 , p. 24). Um momento em que os grupos interagem, expõem, trocam ideias e refletem a respeito das variadas formas de encontrar as soluções almejadas. Em relação a outros conteúdos, além dos matemáticos, dizem respeito ao caráter interdisciplinar de um tema. Conteúdos esses que dizer respeito a aspectos sociais, econômicos, ambientais, que podem dar sentido aos conceitos científicos.

Como alerta Japiassu (1976, p. 40), a "necessidade de reflexão sobre a fragmentação do conhecimento e as possíveis consequências para a formação, além de despertar, para a imprescindibilidade de uma postura interdisciplinar crítica", a Modelagem Matemática, na perspectiva de Burak (2010), busca um ensino com abrangência, sem a fragmentação das disciplinas ocorrida principalmente no século XIX.

Com nova perspectiva de ver e conceber o ensino e aprendizagem de Matemática, "desgarrando-se" da forma cartesiana de tratar os conteúdos em sala de aula, Burak e Martins (2015) destacam a possibilidade de uma formação que envolve competências complexas, por exemplo: coletar dados, organizar esses dados, levantar hipóteses, levantar problemas e solucioná-los; essas são competências denominadas "complexas importantes para o momento do mundo atual" (BURAK e MARTINS, 2015, p. 97), necessárias para os estudantes se tornar buscadores em vez de meros seguidores. Essas competências são "saber observar, explorar e investigar; estabelecer relações, classificar e generalizar e, ainda, favorecer situações que permitam desenvolver capacidades de argumentar, tomar decisões e criticar" (BURAK e MARTINS, 2015, p. 97). Amparados em Morin (2006), argumentam que tais competências podem habilitar os estudantes a enfrentar as incertezas e situações inesperadas com a interpretação de informações acumuladas ao longo do tempo. Os autores ainda defendem que "é, também, uma necessidade de nossos tempos induzir os estudantes às situações desafiadoras, que reclamem 0 uso da imaginação e da criatividade e desenvolvam suas capacidades de expressão, reflexão e crítica" (BURAK e MARTINS, 2015, p. 97).

Isso só será possível se concebermos e passarmos a colocar em prática em sala de aula 
nova forma de currículo, pois, o de forma tradicional não dá sustentação a essas necessidades pontuadas por Burak e Martins (2015). Os estudantes não conseguem perceber o sentido de repetições mecânicas e de algoritmos que não fazem sentido para o ensino de Matemática contemporânea (BURAK e MARTINS, 2015). Uma organização curricular que possibilite aos estudantes o envolvimento dos conteúdos aprendidos na escola com o meio social onde estão inseridos por meio das experiências vivenciadas e da ligação com outras áreas do conhecimento.

\subsection{Teorias curriculares que mais respaldam a implementação da Modelagem Matemática em sala de aula}

Em busca do que vem a ser o currículo, percebemos uma movimentação do Ministério da Educação (MEC) a respeito do tema (BRASIL, 2007). Em um documento organizado por Antônio Flávio Moreira e Miguel Gonzáles Arroyo, intitulado Indagações sobre o Currículo, neste consta que "os currículos não são conteúdos prontos a serem passados aos alunos. São uma construção e seleção de conhecimentos e práticas produzidas em contextos concretos e em dinâmicas sociais, políticas e culturais, intelectuais e pedagógicas" (BRASIL, 2007, p. 9). Os escritos de Arroyo (2007, p. 41) referenciam a Lei de Diretrizes e Bases LDB 9394/96 destacando que esta "se afasta da visão dos educandos como mão-de-obra a ser preparada para o mercado e reconhece que cada criança, adolescente, jovem ou adulto tem direito à formação plena como ser humano".

Em vistas de repensar a forma curricular vigente a partir dos estudantes como sujeitos de direitos, Arroyo (2007) apresenta alguns questionamentos. Ao analisarmos os objetivos da Modelagem Matemática na Educação Matemática entendemos que também se relacionam a esses questionamentos.

Por que não nos atrever a repensar as lógicas do ordenamento escolar e curricular a partir da infância-adolescência sujeitos reais de direitos? O que impede atrever-nos a construir outros ordenamentos mais próximos dos sujeitos reais do direito ao conhecimento, à cultura, à educação? Não seriam a escola, os currículos os obrigados a se adaptar aos sujeitos reais do direito à educação? Por que construir um ordenamento ideal e esperar que as vidas dos sujeitos reais a ele se adaptem? (ARROYO, 2007, p. 40).

O autor ainda nos questiona "Que estrutura curricular dará conta da função específica da escola e do magistério nessa pluralidade de processos formadores? Que peso dar às vivências socializadoras, culturais, cognitivas, construídas na pluralidade de espaços?" (ARROYO, 2007, p. 
42). Isso se remete a algumas formas de currículos presentes na literatura que podem direcionar o trabalho do professor em sala de aula.

Silva (2010) apresenta que o currículo é constituído pelo resultado de uma seleção, "de um universo mais amplo de conhecimentos e saberes seleciona-se aquela parte que vai constituir, precisamente, o currículo", as teorias de currículos é que buscam justificar essa seleção, "por que esses conhecimentos e não aqueles" (p. 15). Conforme o autor, um currículo busca modificar as pessoas que o seguirão, nesse entender sempre as teorias curriculares, ao deduzir os conhecimentos a serem considerados, são direcionadas por questões como, "o que eles ou elas devem ser? ou, melhor, o que eles ou elas devem se tornar?" (SILVA, 2010, p. 15). O autor destaca os interesses do currículo em vista à formação do ser humano:

\begin{abstract}
Qual é o tipo de ser humano desejável para um determinado tipo de sociedade? Será a pessoa racional e ilustrada do ideal humanista de educação? Será a pessoa otimizada e competitiva dos atuais modelos neoliberais de educação? Será a pessoa ajustada aos ideais de cidadania do moderno estado-nação? Será a pessoa desconfiada e crítica dos arranjos sociais existentes preconizada nas teorias educacionais críticas? A cada um desses "modelos" de ser humano corresponderá um tipo de conhecimento, um tipo de currículo (SILVA, 2010, p. 15).
\end{abstract}

Nesse encalço, Silva (2010) apresenta algumas teorias curriculares: tradicionais, críticas e pós-críticas. Conforme o autor, o que separa essas teorias é a questão do poder.

As teorias curriculares tradicionais, "pretendem ser neutras, científicas e desinteressadas" (SILVA, 2010, p. 16), nessa perspectiva o foco principal consiste em "identificar os objetivos da educação escolarizada, formar o trabalhador especializado ou proporcionar uma educação geral, acadêmica, à população" (HORNBURG e SILVA, 2007, p. 61). Essa teoria de currículo preocupase com questões de organização, se concentra mais em questões técnicas, por aceitar o status quo, os conhecimentos e os saberes dominantes. A questão "o quê" é tomada como óbvia (inquestionável), se tem esse conhecimento a ser transmitido qual é a melhor forma para transmitilo? (SILVA, 2010).

Em vista do exposto, as teorias curriculares que podem dar sustentação à Modelagem Matemática na perspectiva assumida são as que se opõem e que foram geradas pelo questionamento à forma tradicional, sendo a teoria curricular crítica e pós-crítica. Essas se preocupam mais com a questão "por quê?", "Por quê esses conhecimentos e não outros? Quais interesses fazem com que esse conhecimento e não outro esteja no currículo? Por quê privilegiar um determinado tipo de identidade ou subjetividade e não outro?" essas teorias "estão 
preocupadas com as conexões entre saber, identidade e poder" (SILVA, 2010, p. 17).

A teoria curricular crítica não é neutra, e não está a serviço dos grupos dominantes. Busca a formação de "sujeitos autônomos, capazes de intervir na realidade existente e transformá-la" (PINHEIRO, 2009, p. 16). Enquanto as teorias tradicionais defendem a aceitação, 0 ajuste e a adaptação, as teorias críticas enfatizam a desconfiança, o questionamento e a transformação radical (SILVA, 2010). A teoria pós-crítica não se impõe como uma questão de superação da teoria crítica, mas busca se combinar "para nos ajudar a compreender os processos pelos quais, através de relações de poder e controle, nos tornamos aquilo que somos" (SILVA, 2010, p. 147).

Pinheiro $(2009$, p. 19) faz uma análise das teorias crítica e pós-crítica tratadas por Silva (2007) e destaca o currículo visto nessa perspectiva "como espaço de poder, de lutas, sendo uma construção social". Na teoria crítica e pós-crítica, é priorizado a "problematização o diálogo, instigando 0 aluno na sua fala com a realidade. 0 professor não reproduz meramente saberem prontos e sistematizados, mas caminha junto com o aluno numa relação com a experiência vivenciada" (PINHEIRO, 2009, p. 19). Isso relacionamos ao que é apresentado por Burak (1992) quando considera que, por meio da Modelagem Matemática, o conhecimento matemático não se restringe ao seu próprio contexto, mas oportuniza ao estudante "relacionar o que é aprendido dentro e fora da escola: uma Matemática construída na interação do homem com o mundo, uma Matemática com história." (p. 55).

É nessa perspectiva que se compreende a Modelagem Matemática, pois, com ela, 0 professor não é mais o centro do processo educacional, mas torna-se o mediador entre o saber científico e o saber dos estudantes, formando-os para desenvolverem consciência de seu papel na sociedade, com capacidade para agir e transformar o que está a sua volta, o que rompe com a perspectiva tradicional de currículo.

\section{Conclusões}

Diante do exposto, tecemos conclusões a partir das questões estabelecidas. Com relação à primeira questão "O que se mostra sobre a Modelagem Matemática na Educação Básica, em relação à organização curricular, em um conjunto artigos analisados?", foi constatada a necessidade de desenvolvimento curricular para a Educação Básica que atente para as características da Modelagem Matemática com o viés da Educação Matemática, isso se evidenciou nos trabalhos de Burak (2010), Burak e Martins (2015), Caldeira $(2004,2005,2015)$, 
Forner (2015) e Oliveira (2017). A partir das ponderações desses autores entendemos que a organização curricular de forma linear e cartesiana não respalda a adoção da Modelagem Matemática na Educação Básica.

Ao retomarmos a segunda questão "Qual forma de organização curricular acomoda as necessidades para a adoção da Modelagem Matemática na Educação Básica?", compreendemos que dentre as teorias de currículo, explicitadas por Silva (2010) e Pinheiro (2009), àquelas que mais se aproximam das pretensões da formação do estudante por meio da Modelagem Matemática são as teorias curriculares crítica e pós-crítica. Essas compreendem o estudante como sujeito autônomo, que pode desenvolver habilidades de criar, inventar, conjecturar e intervir na realidade existente para transformá-la, com consciência social, política e ambiental.

Constatamos uma movimentação por parte do Ministério da Educação (BRASIL, 2007), compreendendo que o estudante tem direito à formação integral e plena como ser humano, e que o modo pelo qual o currículo se desenvolve deve garantir essa formação. Isso propicia respaldo para se pensar uma proposta curricular que atente para as características da Modelagem na Educação Matemática. Acreditamos que se os professores da Educação Básica tiver mais respaldo do ponto de vista curricular, não sendo obrigados a seguir uma lista de conteúdos preestabelecidos, poderão desenvolver de forma mais livre práticas com Modelagem Matemática, bem como de outras tendências metodológicas na Educação Matemática. $\mathrm{O}$ que pode resultar um ensino mais atento para as necessidades dos estudantes como sujeitos de direitos.

Em estudos futuros buscaremos analisar o amparo que a Modelagem Matemática na perspectiva da Educação Matemática tem para ser implementada em sala de aula na Educação Básica segundo a Base Nacional Comum Curricular (BRASIL, 2018). Também, buscaremos explicitar as contribuições da Modelagem Matemática para que os estudantes desenvolvam as competências gerais estabelecidas como meta para a Educação Básica segundo a BNCC.

\section{Agradecimento}

O presente trabalho foi realizado com apoio da Coordenação de Aperfeiçoamento de Pessoal de Nível Superior (CAPES) — Código de Financiamento 001. 


\section{Referências}

ARAGÃO, Rosália Maria Ribeiro. Teoria da aprendizagem significativa de David. P. Ausubel: sistematização dos aspectos teóricos fundamentais. 1976. 109f.Tese (Doutorado em Educação) — Faculdade de Educação. Universidade Estadual de Campinas. Campinas.

ARROYO, Miguel Gonzáles. Indagações sobre currículo: educandos e educadores - seus direitos e o currículo. Brasília: Ministério da Educação; Secretaria de Educação Básica, 2007.

AUSUBEL, David Paul. Aquisição e retenção de conhecimentos: uma perspectiva cognitiva. Tradução de Lígia Teopisto. Lisboa: Plátano, 2003.

BRASIL. Ministério da Educação. Secretaria de Educação Básica. Base Nacional Comum Curricular. Ensino Médio. Brasilia: MEC/SEB, 2018.

BRASIL. Ministério da Educação. Secretaria de Educação Básica. Indagações sobre currículo e educandos e educadores: seus direitos e o currículo. Brasília: MEC/SEB, 2007.

BURAK, Dionísio. A Modelagem Matemática na perspectiva da Educação Matemática: olhares múltiplos e complexos. Educação Matemática Sem Fronteiras, Chapecó, v. 1, n. 1, p. 96-111, jan./jun. 2019.

BURAK, Dionísio. Modelagem Matemática e a sala de aula. In: ENCONTRO PARANAENSE DE MODELAGEM EM EDUCAÇÃO MATEMÁTICA, 1, 2004, Londrina. Anais do I EPMEM. Londrina: UEL, 2004. p. 1-10.

BURAK, Dionísio. Modelagem Matemática sob um olhar de Educação Matemática e suas implicações para a construção do conhecimento matemático em sala de aula. Modelagem na Educação Matemática, Blumenau, v. 1, n. 1, p. 10-27, 2010.

BURAK, Dionisio. Modelagem Matemática: ações e interações no processo de ensino e aprendizagem. 1992. 460f. Tese (Doutorado em Educação) - Faculdade de Educação. Universidade Estadual de Campinas. Campinas.

BURAK, Dionísio. Modelagem na perspectiva da Educação Matemática: um olhar sobre seus fundamentos. UNIÓN, n. 51, p. 9-26, dez. 2017.

BURAK, Dionísio. Uma experiência com a Modelagem Matemática. PRÓ-MAT, Curitiba, v. 1, p. 32-47, 1998.

BURAK, Dionísio; MARTINS, Márcio André. Modelagem Matemática nos Anos Iniciais da Educação Básica: uma discussão necessária. Revista Brasileira de Ensino de Ciência e Tecnologia, Ponta-Grossa, v. 8, n. 1, jan./abr. 2015.

CALDATTO, Marlova Estela; PAVANELLO, Regina Maria; FIORENTINI, Dario. O PROFMAT e a formação do professor de Matemática: uma análise curricular a partir de uma perspectiva processual e descentralizadora. Bolema, Rio Claro, v. 30, n. 56, p. 906-925, set./dez. 2016.

CALDEIRA, Ademir Donizeti. A Modelagem Matemática e suas relações com o currículo. In: CONFERÊNCIA NACIONAL SOBRE MODELAGEM E EDUCAÇÃO MATEMÁTICA, 4, 2005, Feira 
de Santana. Anais da $4^{\mathrm{a}}$ CNMEM — Modelagem Matemática na Educação Matemática: seu papel na formação humana. Feira de Santana: UEFS, 2005, p. 1-12.

CALDEIRA, Ademir Donizeti. Modelagem Matemática, Currículo e Formação de Professores: obstáculos e apontamentos. Educação Matemática em Revista, Brasília, n, 46, p. 53-62, 2015.

CALDEIRA, Ademir Donizeti. Modelagem Matemática: produção e dissolução da realidade. In: ENCONTRO NACIONAL DE EDUCAÇÃO MATEMÁTICA, 8, 2004, Recife. Anais do VIII ENEM Educação Matemática: um compromisso social. Recife: UFPE, 2004, p. 1-11.

CASTRO, Élida Maira Velozo de. Procedimentos dos alunos associados às suas ações cognitivas em atividades de modelagem matemática. 2017. 99f. Dissertação (Mestrado em Ensino de Ciências Naturais e Matemática) — Universidade Estadual do Centro-Oeste. Guarapuava.

CLARETO, Sônia Maria. Educação Matemática e contemporaneidade: enfrentando discursos pósmodernos. Bolema, Rio Claro, v. 15, n. 17, p. 20-39, maio. 2002.

CUOCO, Al; GOLDENBERG, E. Paul; MARK, June. Habits of mind: An organizing principle for mathematics curricula. The Journal of Mathematical Behavior, v. 15, n. 4, p. 375-402, dec. 1996.

D'AMBROSIO, Ubiratan. Educação Matemática: da teoria à prática. 17. ed. Campinas: Papirus, 2009.

DEWEY, John. Vida e Educação. 11. ed. Tradução de Anísio Spínola Teixeira. São Paulo: Melhoramentos, 1978.

FORNER, Régis. Modelagem Matemática e o Currículo Oficial do Estado de São Paulo: investigando possíveis relações a partir do diálogo entre professores. In: ENCONTRO BRASILEIRO DE ESTUDANTES DE PÓS-GRADUAÇÃOO EM EDUCAÇÃO MATEMÁTICA, 14, 2015, Juiz de Fora. Anais do $14^{\circ}$ EBRAPEM - Educação Matemática: diversidades e particularidades no cenário nacional. Juiz de Fora: UFJF, 2015, p. 1-11.

FOUCAULT, Michel. Vigiar e punir: nascimento da prisão. Tradução de Raquel Ramalhete. 40. ed. Petrópolis: Vozes, 2012.

GIL, Antonio Carlos. Métodos e técnicas de pesquisa social. 6. ed. São Paulo: Atlas, 2008.

HIGGINSON, William. On the foundations of Mathematics Education. For the Learning of Mathematics, v. 1, n. 2, p. 3-7, nov. 1980.

HORNBURG, Nice; SILVA, Rubia da. Teorias sobre currículo: uma análise para compreensão e mudança. Revista de Divulgação Técnico-Científica do ICPG, Blumenau, v. 3, n. 10, p. 61-66, jan./jun. 2007.

HUF, Samuel Francisco. Modelagem na Educação Matemática no $9^{\circ}$ ano do Ensino Fundamental: uma perspectiva para o ensino e a aprendizagem. 2016. 134f. Dissertação (Mestrado em Ensino de Ciências Naturais e Matemática) — Universidade Estadual do Centro-Oeste. Guarapuava.

JAPIASSU, Hilton. Interdisciplinaridade e patologia do saber. Rio de Janeiro: Imago,1976. 
KLÜBER, Tiago Emanuel. Uma metacompreensão da Modelagem Matemática na Educação Matemática. 2012. 396f. Tese (Doutorado em Educação Científica e Tecnológica) - Centro de Ciências da Educação. Universidade Federal de Santa Catarina. Florianópolis.

KLÜBER, Tiago Emanuel; BURAK, Dionísio. Concepções de Modelagem Matemática: contribuições teóricas. Educação Matemática Pesquisa, São Paulo, v. 10, n. 1, p. 17-34, jan./jun. 2008.

KOMAR, Marcelo Fabrício Chociai. Modelagem Matemática no processo de ensino e aprendizagem da Matemática no Ensino Fundamental: ações e interações. 2017. 128f. Dissertação (Mestrado em Ensino de Ciências Naturais e Matemática) — Universidade Estadual do Centro-Oeste. Guarapuava.

LEITE, Kátia da Costa. Modelagem Matemática na Educação do Campo: tecendo novos caminhos. 2018. 219f. Dissertação (Mestrado em Ensino de Ciências Naturais e Matemática) — Universidade Estadual do Centro-Oeste. Guarapuava.

MALHEIROS, Ana Paula dos Santos. Delineando convergências entre Investigação Temática e Modelagem Matemática. In: SEMINÁRIO INTERNACIONAL DE PESQUISA EM EDUCAÇÃO MATEMÁTICA, 5, 2012, Petrópolis. Anais do 5 SIPEM. Petrópolis: SBEM, 2012, p. 1-18.

MORAN, José Manuel. Ensino e aprendizagem inovadores com apoio de tecnologia. In: MORAN, José Manuel; MASETTO, Marcos Tarciso; BEHRENS, Marilda Aparecida. (Org.). Novas tecnologias e mediação pedagógica. 21. ed. rev. e atual., 4. reimp. Campinas: Papirus, 2015, p. 11-72.

MORIN, Edgar. Sete saberes necessários à educação do futuro. Tradução de Catarina Eleonora Ferreira da Silva e Jeanne Sawaya. São Paulo: Cortez, 2006.

OLIVEIRA, Wellington Piveta. Prática de Modelagem Matemática na formação inicial de professores de Matemática: relato e reflexões. Revista Brasileira de Estudos Pedagógicos, Brasília, v. 98, n. 249, maio/ago. 2017.

PINHEIRO, Geslani Cristina Grzyb. Teoria curricular crítica e pós-crítica: uma perspectiva para a formação inicial de professores para a educação básica. Analecta, Guarapuava, v. 10, n. 2, p. 11 25, jul./dez. 2009.

SILVA, Roberto Araújo; FRANCO, Maria Amélia do Rosário Santoro. Por uma pedagogia da avaliação educacional: pressupostos epistemológicos, tessituras sociais. e-Curriculum, São Paulo, v. 17, n. 2, p. 748-767, abr./jun. 2019.

SILVA, Tomaz Tadeu da. Documentos de Identidade: uma introdução às teorias de currículo. 3. ed. Belo Horizonte: Autêntica, 2010.

SILVA, Vantielen da Silva. Modelagem Matemática na formação inicial de pedagogos. 2018. $189 f$. Tese (Doutorado em Educação) - Setor de Ciências Humanas, Letras e Artes. Universidade Estadual de Ponta Grossa. Ponta Grossa. 